a specified purity of $99.8 \%$. Solvents were used in pesticide residue grade quality from Merck (Darmstad, Germany). A stock soln. of $10 \mathrm{mg} / \mathrm{ml}$ in the mobile phase was prepared and kept in the refrigerator.

\title{
Liquid Chromatographic Resolution and Bioassay of Napropamide Herbicide Enantiomers
}

\author{
Markus D. Müller*, Rolf Wacker, and Hans-Paul Bosshardt
}

Abstract. The enantiomers of the herbicide napropamide (1) were separated on a $\mu \mathrm{g}$-scale using chiral liquid chromatography and submitted to a bioassay for herbicidal activity using a wheat germ test. Under these conditions, only one enantiomer showed herbicidal activity. The potential for reducing the application rate of pesticides by omitting isomeric ballast is discussed.

\section{Introduction}

The herbicide napropamide $(1,(R, S)$ $N, N$-diethyl-2-(I -naphthyloxy)propionamide) is used for pre-emergent control of annual grasses and sensitive broadleaved weed species in crops such as rapeseed, tobacco and in horticulture [1] at typical rates of $1.1-2.2 \mathrm{~kg} \mathrm{a.i./ha.} \mathrm{It} \mathrm{was} \mathrm{introduced}$ by Stauffer Chemical $C o$. (now $I C I$ ) and is registered under the the trade name $D$ evrinol. Napropamide acts by inhibition of root growth in sensitive species. The biochemical mode of action and selectivity have been studied and are attributed to an activation mechanism in susceptible plants [2] [3].

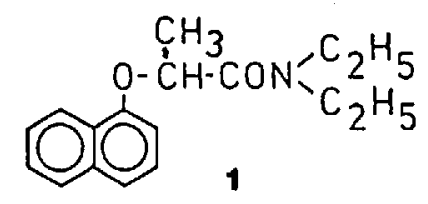

Technical racemic napropamide is produced by reacting $\alpha$-naphthoate with $(R, S)$ 2-bromopropionic acid diethylamide [4]. After application, 1 was found to have a halflife of several months in soil under field conditions [1] [5].

From a chemical point of view, napropamide belongs to the family of aryloxyalkanoic-acid-derived herbicides [6]. Within this family, the group of aryloxypropionicacid derivatives contain a chiral $\mathrm{C}$-atom and has received considerable attention with respect to differences in biological activity of the two enantiomers [7] [8]. In most cases, virtually all herbicidal activity is contained in the $(R)$-enantiomer. This led the pesticide registration authorities of several countries to have racemic phenoxypropionic acids re-

*Correspondence: Dr. M.D. Müller Swiss Federal Research Station CH-8820 Wädenswil placed by a correspondingly reduced amount of pure $(R)$-enantiomers in the formulations. This process is in compliance with legislation in Switzerland [9] and recommendations of international organizations [10]. With napropamide, however, the situation is not so clearcut up to now. There are few papers reporting different biological activities of the two napropamide enantiomers, indicating a ratio of ca. 5-10: 1 for root growth inhibition of the D- and L-form, resp. [2] [11]. On the other hand, a patent to Stauffer Chemical Co. [12] clearly states that only the dextrorotatory form of napropamide exhibits herbicidal activity.

The bioassays reported suffer from the lack of standard material with a high and defined enantiomeric purity, as the enantiomers were obtained by reacting $\alpha$-naphthoate with $(R)$ - or $(S)$-ethyl $O$ - $(p$-toluenesulfonyl)lactate, resp. [11]. The ethyl esters were then converted to the corresponding diethylamides. The enantiomeric excess was determined by measuring the optical rotation, a method which is suitable only when the pure enantiomers are available. Napropamide is prepared by a $S_{N} 2$-type reaction. Nevertheless, some retention is observed [13]. In comparable situations (e.g. synthesis of the herbicides MCPP and dichlorprop), the enantiomeric excess was found to be 90 $95 \%$ [14] [15].

We, therefore, investigated the analytical and semipreparative separation of napropamide enantiomers using chiral HPLC yielding sub-mg quantities of enantiomerically pure $(R)$ - and $(S)$-napropamide. This material was used in a wheat germ biotest to determine the herbicidal activity of the optical isomers.

\section{Experimental}

Standard Material and Solvents

$(R, S)$-Napropamide (1) standard material was obtained from Stauffer ChemicalCo. (Richmond, CA) with
Enantiomer Separation by Liquid Chromatography A Spectra-Physics 8800 type $L C$ pump (SpectraPhysics, San Jose, CA) delivering a flow of $1 \mathrm{~m} / \mathrm{min}$ hexane/i-PrOH 9:1 with a $25 \mathrm{~cm} \times 0.46 \mathrm{~mm}$ Chiralcel OC column (Daicel Chemical Industries, Tokyo, Japan) was used. Samples containing $10 \mathrm{mg} / \mathrm{ml}$ were injected ria a Rheodyne 7125 type injector with a $20 \mu \mathrm{l}$ loop and detected by a Perkin-Elmer (Perkin Elmer. Walnut Creek, CA) type $L C-15$ UV detector at $254 \mathrm{~nm}$. Chromatograms were recorded using a Perkin-Elmer type 56 recorder. Eluates were collected manually after the detector by observing the UV-response during the elution of the first and second eluting enantiomer of napropamide and before the first peak as a control. The enantiomeric purity of a collected napropamide stereoisomer was determined by re-injection and comparison of the peak heights of the desired and undesired enantiomer.

Confirmation and Quantitation of Napropamide Enantiomers Using HRGC-MS

A Carlo Erbagas chromatograph type 5160 (Carlo Erba, Milan, Italy) fitted with an on-column injector and a $20-\mathrm{m} 0.3-\mathrm{mm}$ i.d. glass-capillary column coated with a $0.15-\mu \mathrm{m}$ film of $P S O 86$ was coupled to a Finnigan type 700 ion-trap mass spectrometer. He with a head pressure of $60 \mathrm{kPa}$ served as carrier gas. After injection of the sample $(1 \mu \mid)$ at $60^{\circ}$ oven temp. and ballistic heating to $200^{\circ}$, a temp. program of $5 \%$ min eluted the compound of interest at $c a \cdot 230^{\circ}$. MS were acquired under electron-impact conditions in the range of $m / e$ 60-300. The confirmation and quantitation of the collected LC eluates (after a dilution by a factor of 50 with hexane) was done by comparing the MS and using external standardization on the molecular ion m/e 271 .

Bioassay of the Herbicidal Activity of Racemic and Pure Napropamide Enantiomers

A wheat germ test using winter wheat was used. The seeds ( 12 each) were placed in petri dishes $(9 \mathrm{~cm} \emptyset)$ with two glass-fiber filters. The test soln. containing $0.1,0.5,2.5,5,10$, and $25 \mu \mathrm{g}$ of the napropamide enantiomers or racemare, resp., were evenly distributed onto the filter, and the solvent was allowed to evaporate at $r$. t. Doubly destilled water $(10 \mathrm{ml})$ was added, and the dishes were covered and kept in a climatized room (20$22^{\circ}, 60 \%$ rel. humidity, light $16 \mathrm{~h} / \mathrm{d}$ with an intensity of ca. 6000 lux after an initial period of $48 \mathrm{~h}$ darkness). After $6 \mathrm{~d}$, the shoot length was determined and used for calculation of the relative herbicidal activity. All experiments were carried out in quadruplicate. The four mean shoot lengths of an individual experiment were used to calculate the overall shoot lengths and the respective $90 \%$ confidence intervals.

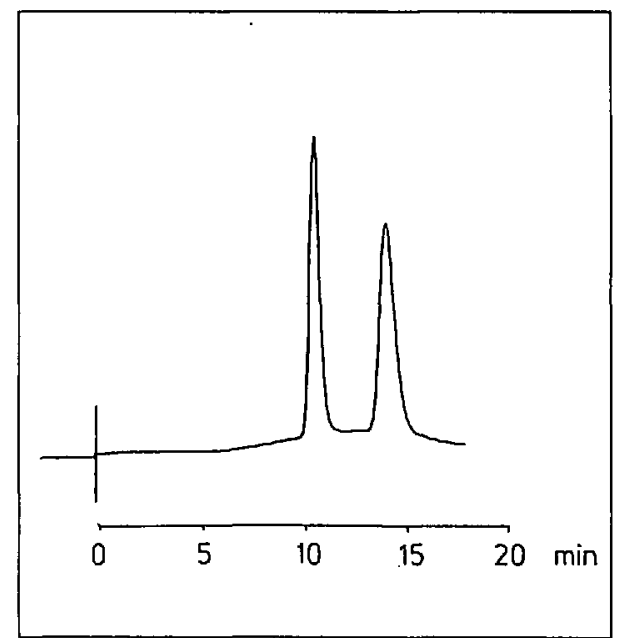

Fig. 1. HPLC chromatogram showing the resolution of napropamide enantiomers. Column: $25 \mathrm{~cm} \times 0.46 \mathrm{~cm}$ Chiralce $O C$. For details. see Experimental. 


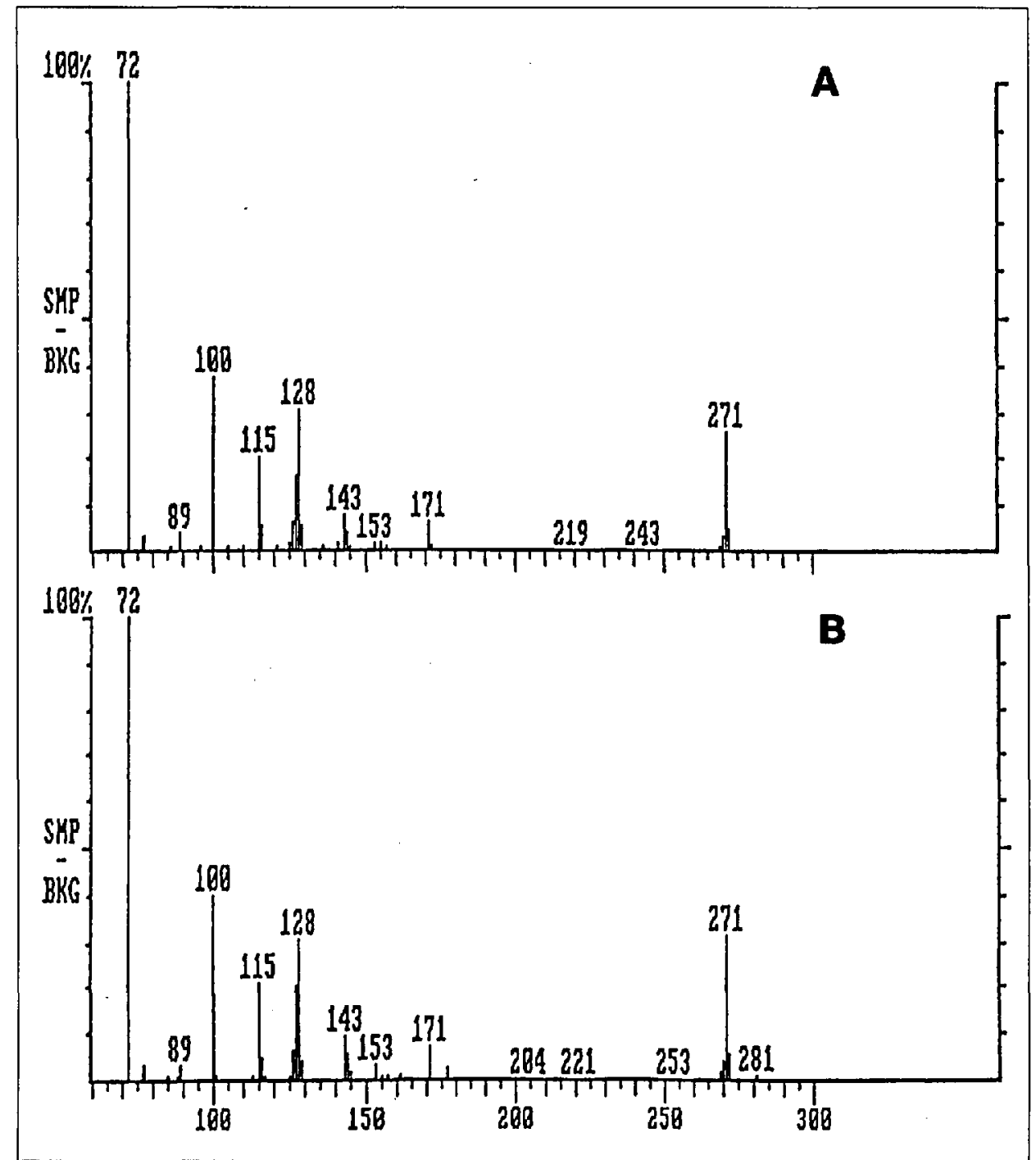

Fig. 2. Mass spectra of napropamide enantiomers: peak $I(A)$ and peak $2(B)$

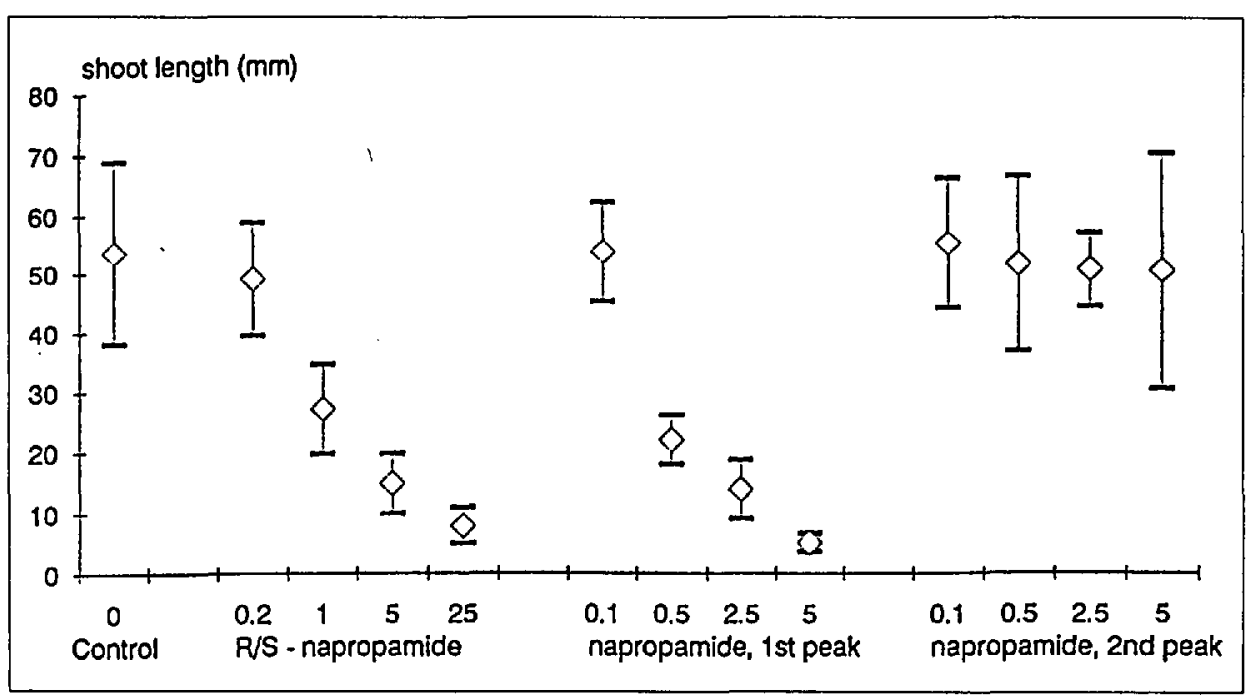

Fig. 3. Mean shoot lengths in mm of wheat germs in relation to napropamide added with confidence intervals $(90 \%)$ indicated. For details, see Experimental.

\section{Results and Discussion}

\section{Napropamide Enantiomer Separation}

The separation of napropamide enantiomers using the chiral LC column Chiralcel $O C$, a modified cellulose carbamate bonded to a silica material, is shown in Fig. I. Under the conditions applied, the optical isomers are well separated with a chromatographic enantiomeric purity of $>99 \%$ or higher for peak 1 and $97 \%$ for peak 2 assuming a limit of detection for $S / N>2$. The lower nominal purity of peak 2 is due to the broader chromatographic signal, yielding a smaller peak height. Due to the lack of authentic $(R)$ - and $(S)$-napropamide, it was not possible to establish the absolute configuration. We, therefore, use the designation 'peak 1' and 'peak 2 ', resp., throughout this work to denote the two enantiomers.

\section{Confirmation of Identity of Napropamide and Quantitation Using HRGC/MS}

The two eluates and a control solution (eluate from the HPLC collected before elution of peak 1 ) were submitted to HRGC/ MS using achiral gas chromatography. A standard solution of authentic napropamide was used for confirmation of the identity of the enantiomers as well as for quantitation purposes. The mass spectra of peak 1 and 2 , corresponding to $c a .1 \mathrm{ng}$, are shown in Fig. 2. Napropamide gives rise to a rather abundant molecular ion at m/e 27l. The jon at m/e 128 stems from the naphthyl moiety, whereas the base peak at m/e 72 is produced by the diethylamine part of the molecule. Obviously, the two enantiomers yield a very similar mass spectrum. The data from GC/ MS allow the confirmation of the enantiomers of napropamide being present in the solutions peak 1 and 2 as well as quantitation of these enantiomers. The solution peak 1 was found to contain $53 \mathrm{ng} / \mu \mathrm{l}$ and peak 250 $\mathrm{ng} / \mu \mathrm{l}$ napropamide enantiomers, resp. No napropamide (less than $0.02 \mathrm{ng} / \mu \mathrm{l}$ ) could be detected in the control solution.

Bioassay of Herbicidal Activity of Racemic and Enantiomerically Pure Napropamide

A wheat germ test was carried out using racemic napropamide, peak 1 and 2 and two types of a control (mobile phase and distilled water). After $6 \mathrm{~d}$, the length of roots and shoots was determined. Though napropamide acts as root growth inhibitor, the effects of the various napropamide concentrations on root formation showed a high variability. In constrast, we found the effect on shoot length much more reproducible. The results expressed as mean shoot length with $90 \%$ confidence intervals are given in Fig. 3. Whereas the control, aliquots of the LC mobile phase collected, do not show a herbicidal effect, racemic napropamide as well as the enantiomer contained in solution peak 1 exhibit a clearcut herbicidal activity. The confidence intervals are much larger at low inhibition than compared to high inhibition. It is interesting to note, that 5 and $2.5 \mu \mathrm{g}$ of racemic and pure enantiomer (peak 1), resp., result in a similar growth inhibition whereas the other enantiomer (peak 2) does not show a significant effect. In terms of shoot growth inhibition, $2.5 \mu \mathrm{g}$ of the active enantiomer produce a $74 \%$ inhibition as does $5 \mu \mathrm{g}$ of the racemate, whereas the inactive enantiomer does not show any significant herbicidal activity. 
From these results, the configuration of the first eluting and herbicidally active enantiomer can be assumed to be (-)-D-isomer. However, there is some confusion in the literature, as in the paper of Chan et al. [11] describing the synthesis of napropamide enantiomers, the herbicidally active D-stereoisomer was found levorotatory $\left([\alpha]_{20}^{\mathrm{D}}=\right.$ -121.35 ), whereas a patent to Stauffer mentions the dextrorotatory form as being the active one [12]. This situation clearly illustrates the necessity of using unambiguous designations for stereoisomers, as stated in a recent report of the WHO expert committee [10]. To our knowledge, the absolute configuration according to the rule of Cahn, Ingold, and Prelog [16] of the herbicidally active isomer has not yet been published.

In conclusion, the data presented in this paper indicate a considerable difference in the herbicidal activities of $(R)$ - and $(S)$-napropamide with, at lower concentrations, virtually all herbicidal activity being present in one enantiomer. However, we are fully aware of the complexity of transferring laboratory data to field experiments, as other mechanisms such as racemization or stereochemical inversion in soil [17], in plants and animals [18] or different uptakes of enantiomers [19] may strongly influence the biological activity of optically active pe- sticides under field conditions. Therefore, these findings would require a verification under field conditions. Nevertheless, we are convinced that a careful evaluation of desired and undesired biological activities including the possibly different environmental fate of optical isomers is an important tool for a deeper understanding of environmental effects and fate of pesticides and is currently implemented in the pesticide registration procedure in Switzerland.

This work is part of a joint project of the Federal Office for Environmental Protection (BUWAL) and of the Research Station for evaluation of the potential for reducing pesticides application by omitting isomeric ballast where one of us $(R . W$.$) is engaged. The support$ of $B U W A L$ is kindly acknowledged. We wish to thank $E$. Barben for carrying out the bioassay of the napropamide samples.

Received: February 26, 1991

[1] 'Herbicide Handbook of the Weed Science Society of America', 6th edn., Chairman N.E. Homburg, Champaign, USA, 1989, p.191.

[2] F.M. Ashton, R. K. Glenn, J. Plant Growth Regul. 1982, I, 277

[3] K. Kobayashi, K. Ichinose, WeedRes. (Japan) 1982, 29, 38.

[4] M. Sittig, 'Pesticides Process Encyclopedia', Noyes Data Corporation, Park Ridge, 1977, pp. 342-343.
[5] R.R. Romanowski, A. Borowy, Weed Sci. 1979. 2,151

[6] S.O. Duke, W.H. Kenyon, in 'Herbicides, Chemistry, Degradation, and Mode of Action', Eds. P.C. Kearney and D.D. Kaufmann, Marcel Dekker, Inc., NewYork, 1988, p. 72.

[7] J.D. Naber, J.J.S. van Rensen, in 'Chemicals in Agriculture, Stereoselectivity of Pesticides', Eds. E.J. Ariens, J.J.S. van Rensen, and W. Welling, Elsevier, Amsterdam, 1988, Vol. I, pp.266-268.

[8] R. Wegler and L. Eue, in "Chemie der Pflanzenschutz- und Schädlingsbekämpfungsnittel', Ed. R. Wegler, Springer, Berlin-Heidelberg-New York, 1970, Vol. 2, p. 278.

[9] Swiss Federal Law on Environmental Protection, Berne, 1983.

[10] 'Chemistry and Specifications of Pesticides', 13 th Report on the WHO Expert Committee on Vector Biology and Control, Geneva, 1990.

[11] J.H.H. Chan, F. Walker, Chj.K. Tseng, D.R. Baker, D.R. Ameklev, I. Agric. Food Chem. 1975, 23, 1008

[12] S.K. Dahod, to Stauffer Chemical Company, U.S. Patent 4'613'690, 1986.

[13] S.H. Pine, 'Organic Chemistry', 5th edn., McGraw Hill, New York, 1987, p. 322.

[14] M.D. Müller, H.-P. Bosshardt,J.Ass.Off.Anal. Chen. 1988, 71, 614.

[15] M. Liesner, personal communication (BASF $A G$, Limburgerhof, Germany)

[16] R.S. Cahn, C. Ingold, V. Prelog, Angew'. Chem. Int. Ed. 1966, 5, 385.

[17] D.W. Bewick, Pestic. Sci. 1986, 17, 349

[18] W.J.Wächter, D.G. Loughhead, R.J. Reischer, G.J. VanGiessen, D. G. Kaiser, Biochem. Biophys. Res. Conmun. 1974, 61, 833.

[19] A. Sioufi, D. Golussi, F. Marfil, J.P. Dubois, $J$. Chromatogr. 1987, 4/4, 131 thiolates [6a], and we now report similar effects in the reaction with tetrachloro- and tetrabromo phthalimides and anhydrides.

\section{Results and Discussion}

In several cases, isolated alkali thiolates were used as nucleophiles [2][8]. We prefer to prepare the thiolate anions in situ by adding a base (mostly anhydrous $\mathrm{K}_{2} \mathrm{CO}_{3}$, in one case $\left.\mathrm{Et}_{3} \mathrm{~N}\right)$ to the reaction mixture [1][6a]. When stirred with tetrachloro- or tetrabromophthalic anhydrides or imides 1 (Scheme) in THF, mono- and dithio-substituted derivatives $\mathbf{2}$ and $\mathbf{3}$ can be prepared regio- and chemoselectively depending on reagents, stochiometry, and reaction conditions (Table l) $[9][10]$.

If $\mathrm{ca}$. 1 equiv. of a thiophenol bearing in 4-position a $+l$ - or $+M$-substituent (such as $\mathrm{Me}$ or $\mathrm{MeO}$ ) is used the monosubstitution products 2 can be isolated in fair yields.

ments [5], thioxanthone photosensitiz [1][6], and in the synthesis of natural products [7]. In polyhalogen compounds, some chemo- and regioselectivities were found, e.g. in tetrahalo cyanobenzoates [5], polychlorobenzenes [3], or halogenated pyridines [2a].

We recently found particularly high regioselectivities in the reaction of 3,5-dinitrophthalimides and -anhydrides with
*Correspondence: Dr. W. Fischer

Ciha-Geigy Lid.

$\mathrm{CH}-4002$ Basel

")Dr. T. Winkler

FD Physics Department

Ciba-Geigy Lid.

$\mathrm{CH}-4002$ Basel
Central Research Laboratories wide range of applications, e.g. in the fields of polymer synthesis [4], preparation of pig- 
From these results, the configuration of the first eluting and herbicidally active enantiomer can be assumed to be (-)-D-isomer. However, there is some confusion in the literature, as in the paper of Chan et al. [11] describing the synthesis of napropamide enantiomers, the herbicidally active D-stereoisomer was found levorotatory $\left([\alpha]_{20}^{\mathrm{D}}=\right.$ -121.35 ), whereas a patent to Stauffer mentions the dextrorotatory form as being the active one [12]. This situation clearly illustrates the necessity of using unambiguous designations for stereoisomers, as stated in a recent report of the WHO expert committee [10]. To our knowledge, the absolute configuration according to the rule of Cahn, Ingold, and Prelog [16] of the herbicidally active isomer has not yet been published.

In conclusion, the data presented in this paper indicate a considerable difference in the herbicidal activities of $(R)$ - and $(S)$-napropamide with, at lower concentrations, virtually all herbicidal activity being present in one enantiomer. However, we are fully aware of the complexity of transferring laboratory data to field experiments, as other mechanisms such as racemization or stereochemical inversion in soil [17], in plants and animals [18] or different uptakes of enantiomers [19] may strongly influence the biological activity of optically active pe- sticides under field conditions. Therefore, these findings would require a verification under field conditions. Nevertheless, we are convinced that a careful evaluation of desired and undesired biological activities including the possibly different environmental fate of optical isomers is an important tool for a deeper understanding of environmental effects and fate of pesticides and is currently implemented in the pesticide registration procedure in Switzerland.

This work is part of a joint project of the Federal Office for Environmental Protection (BUWAL) and of the Research Station for evaluation of the potential for reducing pesticides application by omitting isomeric ballast where one of us $(R . W$.$) is engaged. The support$ of $B U W A L$ is kindly acknowledged. We wish to thank $E$. Barben for carrying out the bioassay of the napropamide samples.

Received: February 26, 1991

[1] 'Herbicide Handbook of the Weed Science Society of America', 6th edn., Chairman N.E. Homburg, Champaign, USA, 1989, p.191.

[2] F.M. Ashton, R. K. Glenn, J. Plant Growth Regul. 1982, I, 277

[3] K. Kobayashi, K. Ichinose, WeedRes. (Japan) 1982, 29, 38.

[4] M. Sittig, 'Pesticides Process Encyclopedia', Noyes Data Corporation, Park Ridge, 1977, pp. 342-343.
[5] R.R. Romanowski, A. Borowy, Weed Sci. 1979. 2,151

[6] S.O. Duke, W.H. Kenyon, in 'Herbicides, Chemistry, Degradation, and Mode of Action', Eds. P.C. Kearney and D.D. Kaufmann, Marcel Dekker, Inc., NewYork, 1988, p. 72.

[7] J.D. Naber, J.J.S. van Rensen, in 'Chemicals in Agriculture, Stereoselectivity of Pesticides', Eds. E.J. Ariens, J.J.S. van Rensen, and W. Welling, Elsevier, Amsterdam, 1988, Vol. I, pp.266-268.

[8] R. Wegler and L. Eue, in "Chemie der Pflanzenschutz- und Schädlingsbekämpfungsnittel', Ed. R. Wegler, Springer, Berlin-Heidelberg-New York, 1970, Vol. 2, p. 278.

[9] Swiss Federal Law on Environmental Protection, Berne, 1983.

[10] 'Chemistry and Specifications of Pesticides', 13 th Report on the WHO Expert Committee on Vector Biology and Control, Geneva, 1990.

[11] J.H.H. Chan, F. Walker, Chj.K. Tseng, D.R. Baker, D.R. Ameklev, I. Agric. Food Chem. 1975, 23, 1008

[12] S.K. Dahod, to Stauffer Chemical Company, U.S. Patent 4'613'690, 1986.

[13] S.H. Pine, 'Organic Chemistry', 5th edn., McGraw Hill, New York, 1987, p. 322.

[14] M.D. Müller, H.-P. Bosshardt,J.Ass.Off.Anal. Chen. 1988, 71, 614.

[15] M. Liesner, personal communication (BASF $A G$, Limburgerhof, Germany)

[16] R.S. Cahn, C. Ingold, V. Prelog, Angew'. Chem. Int. Ed. 1966, 5, 385.

[17] D.W. Bewick, Pestic. Sci. 1986, 17, 349

[18] W.J.Wächter, D.G. Loughhead, R.J. Reischer, G.J. VanGiessen, D. G. Kaiser, Biochem. Biophys. Res. Conmun. 1974, 61, 833.

[19] A. Sioufi, D. Golussi, F. Marfil, J.P. Dubois, $J$. Chromatogr. 1987, 4/4, 131 thiolates [6a], and we now report similar effects in the reaction with tetrachloro- and tetrabromo phthalimides and anhydrides.

\section{Results and Discussion}

In several cases, isolated alkali thiolates were used as nucleophiles [2][8]. We prefer to prepare the thiolate anions in situ by adding a base (mostly anhydrous $\mathrm{K}_{2} \mathrm{CO}_{3}$, in one case $\left.\mathrm{Et}_{3} \mathrm{~N}\right)$ to the reaction mixture [1][6a]. When stirred with tetrachloro- or tetrabromophthalic anhydrides or imides 1 (Scheme) in THF, mono- and dithio-substituted derivatives $\mathbf{2}$ and $\mathbf{3}$ can be prepared regio- and chemoselectively depending on reagents, stochiometry, and reaction conditions (Table l) $[9][10]$.

If $\mathrm{ca}$. 1 equiv. of a thiophenol bearing in 4-position a $+l$ - or $+M$-substituent (such as $\mathrm{Me}$ or $\mathrm{MeO}$ ) is used the monosubstitution products 2 can be isolated in fair yields.

ments [5], thioxanthone photosensitiz [1][6], and in the synthesis of natural products [7]. In polyhalogen compounds, some chemo- and regioselectivities were found, e.g. in tetrahalo cyanobenzoates [5], polychlorobenzenes [3], or halogenated pyridines [2a].

We recently found particularly high regioselectivities in the reaction of 3,5-dinitrophthalimides and -anhydrides with
*Correspondence: Dr. W. Fischer

Ciha-Geigy Lid.

$\mathrm{CH}-4002$ Basel

")Dr. T. Winkler

FD Physics Department

Ciba-Geigy Lid.

$\mathrm{CH}-4002$ Basel
Central Research Laboratories wide range of applications, e.g. in the fields of polymer synthesis [4], preparation of pig- 